\title{
The Anxiety-Provoking Risks of Performance Management and Its Alternative Solutions in the Banking Environment
}

\author{
Rene Santenac \\ University of the West Indies \\ Center for Research on Economy, Law and Island Development
}

The theory of performance has a unique character as it has allowed the creation of large organizations. It borrows from economic theory the criteria of effectiveness and efficiency. Performance theory itself has a sound foundation, particularly, financial and accounting ones without taking into account its global field of investigation: the organization and the man. In other words, this part of psychology acts and interacts with the organization.

This article pursues four main objectives. First, it reminds the central elements of the theory of performance regarding the "capabilities" of "stakeholders." Second, it aims to identify the factors of performance failure caused by a lack of consideration of global criteria to build a coherent model of optimal management. Third, it maps the risks caused by defects, differences, and gaps in performance management. Finally, it tries to provide an alternative plausible solution to establish more effective performance management. The primary domain is management science while the input from psychology remains limited and applicable only to specific elements such as psycho-social phenomena.

Keywords: managerial performance, anxiety, effectiveness, efficiency, psycho-social risks, human behavior

\section{INTRODUCTION}

Performance management is a primary concern for all companies and has become the focus of management over the past twenty years. Indeed, quality performance management is an important lever for any business leader.

However, performance management, which measures the degree of achievement of the company's objectives and its degree of success and satisfaction, has also become a strategic element in the individual management of the work and activity of the employee, and is based on a triptych vision of management: the objective, the activity, and the short- and medium-term results within the company.

PM creates a whole system of rights and duties between the parties, e.g., shareholders-managers, directors-managers, managers-collaborators, and collaborators-collaborators. These principles of law and duty have profoundly changed the quality of the relationship between actors. This is what the agency theory demonstrates in the context of the relationship between the principal and the agent (Jensen \& Meckling, 1976). Indeed, this theory defines the problem that an economic actor may encounter vis-à-vis another actor. The first is referred to as the "principal" and the second as the "actor." In the case of our study, the principal is the manager, the pilot of the performance, and the actor is the collaborator. The principal is 
imperfectly informed of the negative effects that his action can have on the actor. This involves studying the risks generated by overly exaggerated management that induce anxiety and underperformance due to informational asymmetry between the two economic agents in the relationship within an organization.

These problems can be of three kinds. The first, "anti-selection," creates the opposite effect of effective performance management. Second is the "moral hazard" or the moral risk of seeing the employee behaving differently or as lacking ethical behavior. The third is a "signal problem," where the agent with information useful to the principal refuses to pass it on to him, thereby creating a risk in operational execution.

Sometimes the decisions and the management method are clear when they are shared and sometimes they are not, which can create a moral risk that can have harmful consequences for the company to the point of destroying it.

The concern for the quality of the relationship between the actors and the related methods is important because, in some cases, they can lead to poor performance or even generally lead to chaos and the destruction of the company.

When the manager's directive is well lived and shared by the greatest number, it leads managers and their employees to surpass themselves and brings about positive and historic results that ensure sustainability, well-being, and happiness of the employees. This is demonstrated by the success of a large number of businesses regardless of their size.

Moreover, when a directive is misunderstood and, above all, badly experienced by the employee, it generates fear and anxiety in them, resulting in a large number of signs (frequent sick leave, demotivation, stress, delays, withdrawal), which can ultimately lead the company to disaster. Under these conditions, the manager no longer controls the performance of his employees but instead deals with their anguish, anxiety, and desire to do the minimum work as opposed to working toward the optimum.

In this case, we can speak of the limited rationality of the actors, particularly that of the manager who drives the performance. It depends on a large number of parameters, both endogenous and exogenous, which is a principle developed by Simon (1955). In fact, within the framework of performance management, the manager is limited in his choice of decisions due to the limits of his own cognitive capacities and the information at his disposal. Some decisions can be unfortunate and have a negative impact on the employee. Similarly and symmetrically, the manager's behavior may be biased due to presupposed information from his employee, so he will then adopt choices that may not be optimal. Nevertheless, the limited nature of rationality allows in certain circumstances to make good decisions.

These concerns about performance management failures stem from the failure to take into account the human dimension: eagerness to learn, to progress, and especially to share the benefits of the company. In other words, humans have their own internal logic, which is a limited rationality because they are divided between their desires, their needs, their cognitive sense, the realization of their own individual being, and their social recognition.

So how can performance management be placed at the heart of decision-making so that it satisfies the parties involved in a constantly changing world? The equation is just as complex to solve when it pits business strategy against individual satisfaction needs. Competition and cooperation are the intelligence of a system that will make the vision clearer. This is the meaning of action research that should make it possible to find avenues for alternative solutions.

After having laid the theoretical foundations of performance management, based on the theory of the HR firm, Coase (1937) and that of Mintzberg (1982), where we will see why the organization must be responsible, in the same sense of the degree of responsibility expected by individuals, we will examine the limits of the model. Then, the exploratory analysis will allow us to map the risks generated by performance management and the warning signs it gives off. Through "action research," we will highlight avenues for alternative solutions.

\section{The Theoretical Bases of Performance Management}

Management, whose role "is to understand in order to act on what makes people mobilize in order to achieve a goal" must play a key role in achieving optimal performance. Management is the product of 
human activity, therefore, it is an art and is particularly aimed at the senses, emotions, intuitions, and the intellect of each individual in order to achieve the best possible result.

However, the achievement of positive results by the company is most often seen as a factor of good performance for the shareholder, so it is the quantitative aspect that is put forward to the detriment of the overall approach.

The concept of performance, therefore, has various aspects. It is linked both to the objectives and to the evaluation of the standards that established by management. These standards are both quantitative and qualitative. When they are quantitative, they are linked to activity and result indicators; when qualitative, they relate to a value judgment.

Performance is a global concept and does not stop with the profitability of the company. It imposes a whole system of rights and duties between the parties that management intends to develop.

We can validly associate performance management science with the concept of efficiency and effectiveness of economics. However, there are differences. Effectiveness is the ability to achieve goals and efficiency depends on the use of tools to achieve a result. It is measured between the result obtained and the resources used.

It is therefore necessary to distinguish individual performance, which relates to the ability of each employee to surpass themselves, from collective performance, which represents the value of the unit produced of goods and services.

This distinction comes from the use of the word "performance." In French, it is linked to the achievement of a result; in English, it refers to notions of behavior. In chemical engineering, for example, performance represents the production target.

We will therefore retain that performance takes on a plural and global character of combinations of multiple factors, the success of which depends on an intelligent articulation between the systems of governance, production, sales, strategy, and foresight; hence, its etymology in Old French "parformer," which means "to accomplish."

Performance is therefore intimately linked to a process, exercised by management, which leads to conditions specific to its transformation and success through an organizational learning function. If the goal is to achieve a $10 \%$ growth rate in turnover at the end of the period, then performance management will consist of putting in place tools and methods to get there.

If, however, the score achieved is lower than the objective, then the performance criterion retained will not be met. We can judge the level of performance of the company and its ability to achieve such a result. It will be necessary either to put in place the means to achieve it or to analyze the realistic and achievable objective factors. In this sense, performance management has a dual character: it must be both responsible and objective.

The object of our research is to establish the theoretical bases of performance management, its modus operandi and its methodology. Therefore, it is necessary to establish sufficiently powerful compatible rules to validate the robustness of the entire performance management system.

First of all, we will retain that performance management must respect observable, measurable, or even refutable criteria. The elements that make it possible to calculate the differences between the objectives pursued and the objectives achieved, without these differences always being the same over the years, provide more reliable information to the observed organization. It is also necessary to ensure the precision and validity of the measurements in order to extract viable and acceptable coefficient rates from them. Finally, the criteria used must represent well all the dimensions of performance.

Both analytical and operational research has shown a great diversity linked to this concept of performance management and the difficulty of finding consensus probably due to the multidisciplinary nature of the concept itself.

Indeed, many schools have looked into the question of organizational performance, its evaluation, its effectiveness, and its relevance. We can highlight pele mixes two major distinct conceptions.

On the one hand, the school of classical organization theory, coming from Fayol, Weber, and Taylor, considers the organization as an economic unit based on criteria of objectives and results. 
On the other hand, the theory of human relations (early 1930s), represented by Mayo, Maslow, McGregor, and Likert, has put forward the human dimension of the organization, placing the individual employee at the center of decision-making and aiming at the fulfillment and satisfaction of employees' personal needs beyond the objective of the organization.

Other schools of thought have emerged, such as Von Bertalanfly's systems thinking school in the $1950 \mathrm{~s}$, which defined the organization as a model of survival to be achieved.

We can also cite "stakeholder theory," which emerged as an alternative model through the prism of the sacred idea of social responsibility. This theory is defended by Mercier (1999) and Caroll (1989) who consider that stakeholders comprise "all the agents for whom the development and good health of the company are important issues." These authors distinguish between the so-called "primary" stakeholders who have a direct interest in the management of the performance of the company because of their contractual relationship and the so-called "secondary" stakeholders who have an indirect link with the effectiveness of performance management. This theory develops the idea that the influence of invisible bodies having a particular interest in the business can harm the business more than the visible bodies themselves that work in the best direction of performance. It is also the idea that all the partners of the company, particularly the social partners, are not integrated in the construction of performance management and, therefore, have an attitude contrary to the objectives.

Other authors, such as Morin, Savoie, and Beaudin, have defined criteria to measure performance using performance indicators, such as sustainability, economic efficiency, product quality, financial profitability, competitiveness, and the human resource value and its legitimacy.

However, it is precisely this last dimension in the organization that remains difficult to measure, to the point of creating disruptive effects. It is these disruptive effects that mark the limits of the performance management model that we must analyze.

\section{The Limits of Performance Models and Their Scope}

Indeed, the resource value put forward cannot perceive or anticipate the effects of disruption between the organization and the person, the employee, and between the manager and his employee. Undoubtedly, due to the fact that the criteria of measures - staff mobilization, staff morale, staff performance, individual development and self-realization - are more or less put forward. It is these effects that create ruptures, even rifts between the manager and his employee to the point where performance management becomes discriminating, inefficient, and leads to perverse effects.

In addition, performance management essentially concentrates its efforts on the satisfaction of its third parties (customers, suppliers, regulatory bodies, local authority bodies), which is undoubtedly normal.

Therefore the evaluation of the performance of an organization is determined, on the one hand, by endogenous criteria of quantitative accounting, such as turnover, added value, and results, and on the other hand by exogenous orders of statistics such as the degree of customer satisfaction or loyalty rate. The performance appraisal does not always take into account specific criteria related to the staff themselves, such as those indicated above. This simple limit makes it clear that performance management can be exercised in a discriminatory manner and thus generates frustration, fear, isolation and, consequently, a decrease in employee productivity.

There is an insufficiency, even a dead end, in taking into account the dimensions that make up the evaluation of performance management. To do this, it is necessary to set up a matrix comprising its main measurement elements.

Performance indicators depend on instruments or information collection to make them relevant, and have an operational, measurable, and quantifiable nature. For example, in a sample of 88 people we interviewed, $7 \%$ of people say they feel anxiety when the pecking order is insistent while $16 \%$ admit to feeling stress in such circumstances. The aggregation of these results shows that $22.7 \%$ of those questioned felt that they released stress and anxiety in the face of oppressive performance management. Of the $22.7 \%$ of people releasing stress and anxiety, $6 \%$ of them tend to isolate themselves when the hierarchical recommendation is strong while $18 \%$ of these people feel they have a hard time managing their emotions in a situation of oppressive and uncommunicative management. It should also be noted that $66 \%$ of the 
sample believe that they manage their emotions in a normal way and $11 \%$ even take pleasure in the face of demanding and oppressive management. Aggregating these results shows that $77.3 \%$ are able to manage their emotions.

These results show two trends; on the one hand, the more the hierarchy sins in its communication, the more employees are likely to develop anxiety balls and stress at work. On the other hand, the more the pressure is felt, the more the employee isolates and withdraws. From this survey, we can modestly conclude that there is correlation among the lack of communication from the hierarchy, the loss of employee confidence, and the ineffectiveness of performance managerial action.

Moreover, numerous studies and recent cases have confirmed the link between stress and performance, notably through the known cases of France Telecom (now Orange), Renault, and many others. These cases show that when executives engaged in a performance research process that was poorly understood or poorly communicated, a certain number of these employees committed suicide because they did not reach the objectives imposed by their hierarchy, thus weighing on their careers. We therefore speak of moral harassment at work, which puts managers and their employees under pressure leading to poor performance. However, justice has not yet decided on the existing links between the suicides observed and management within the framework of France Telecom (Orange). It should be noted, however, that the cases of suicides amounted to more than 30 in 2 years in this company.

In France, there are between 300 to 400 suicides per year in many large companies such as the Post Office, EDF, GDF-Suez, Fnac, the Police, and the banks.

Not all suicides are due exclusively to performance management objectives, but more than $80 \%$ of these cases concern it, i.e., 240-320 people.

More generally, it is article L 1152-1 (ordinance of March 13, 2007, amended by law no. 2012-954 of August 6, 2012) of the Labor Code that defines the framework for harassment according to the following principle: "No employee must be subjected to repeated acts of moral harassment which have as their object or effect a degradation of their working conditions likely to infringe their rights and dignity, alter their physical or mental health or compromise their professional future."

First, this definition highlights the unpleasant and harmful effects on the person considering themselves to be a victim. Second, the question of the duration is induced in the definition by the character "repeated"; that is to say, at least twice, whether the duration is short or long.

All these elements show the potential risks that exist and the limited nature of ineffective performance management. As a result, risks arise from the deadlock that is most often made on the lack of integration of staff in the process of constructing the criteria that make up performance management as well as the conditions linked to its achievement.

Organizational performance is not only and exclusively mathematical, economic, accounting, and financial; it includes a whole global process by actors and tools. In this sense, the work of Michel Lebas shows that the effectiveness of management performance lies in the choice of indicators: "Performance is not a simple observation, it is built. It is the result of a causal process. Thus it is an indication of a potential for future results and is defined by a vector of parameters reflecting a causal model in space and time."

It cannot be limited to the construction of a dashboard to control the degree or effectiveness of performance management unless the model takes into account the general mapping of risks that it may develop. It is this mapping that needs to be analyzed.

\section{Mapping of Anxiety-Provoking Performance Risks}

Anxiety phenomena can be qualified as "psycho-social risks," says RPS. These are, according to INSERM, "all the elements that undermine the physical integrity and mental health of employees within their professional environment." They are of several types:

- Stress: comes from an imbalance between the constraints imposed by professional activity, time management, conflicts with hierarchy or colleagues and the resources and human quality of a person. There are two types: acute stress, which is linked to a one-off situation, and chronic stress, which comes from the repetitive nature of an injunction. 
- "Burnout": results from a situation of prolonged stress in connection with a significant personal and emotional investment in professional activity.

- Moral harassment: is a concept from the prodigious work of Heinz Lezmann, known under the term "mobbing," which means for a person to find himself under the coercion of several others or the fact of deliberately harming an individual in his professional function.

- Violence at work: can come from inside or outside (customers, suppliers, third parties, etc.) from psychological and even physical pressures, without the victim necessarily being considered fragile.

All of these elements cause pathological disorders in individuals such as depression, sleep disorders, musculoskeletal disorders, and psychosomatic illnesses. They come from both an individual, collective, and organizational proliferation inherent in professional activity, which explains their complexity.

To speak of risk mapping in performance management in this way is to integrate the idea of a spatial dimension linked to hazards but also to business issues. It is also to identify the degree of vulnerability of the company around three factors:

- Spatial dimension of global risks

- Development of a prevention plan on risk management

- Determination of a strategy for anticipating the risk of performance default.

The example of health establishments is enriching to support our point. Indeed, healthcare establishments have set up an entire detection system for the treatment of adverse events liable to deteriorate the environment and thereby create nosocomial infections. The success of such an operation stems from the establishment of a program and a comprehensive risk prevention system within the hospital environment. The watchword is the practice of anticipations based on "a priori risk assessment" by precise and predefined criteria.

To identify the risks of performance management, it is necessary to map the area of resource management and particularly of the employee, without ever infringing on their autonomy and freedom. Obviously, the scope of the methodology and level of detail must be developed.

The first step, in our opinion, is to build a Preliminary Risk Analysis, called APR, and then identify the anxiety-inducing failure model (MDA), which can be detected in this way.

To meet this first objective, the cartographic approach is useful. That is to say, it must respect a scheme and a process, starting from the identification and going up to the development of an action plan according to the following scheme:

FIGURE 1

PRELIMINARY RISK ANALYSIS (APR) TEMPLATE

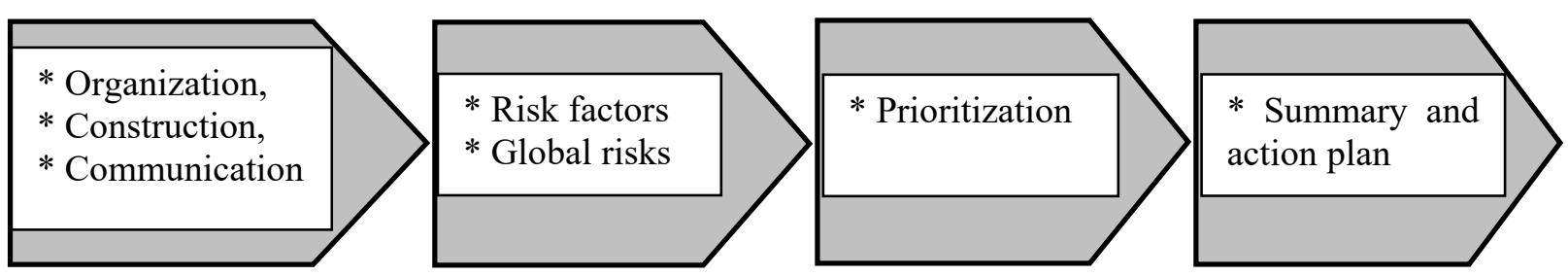

The RPA, therefore, consists in having a good knowledge of the organization and the system put in place in order to jointly develop a functional analysis and a technical tree structure according to the following diagram : 
FIGURE 2

TECHNICAL STRUCTURE OF PERFORMANCE CRITERIA

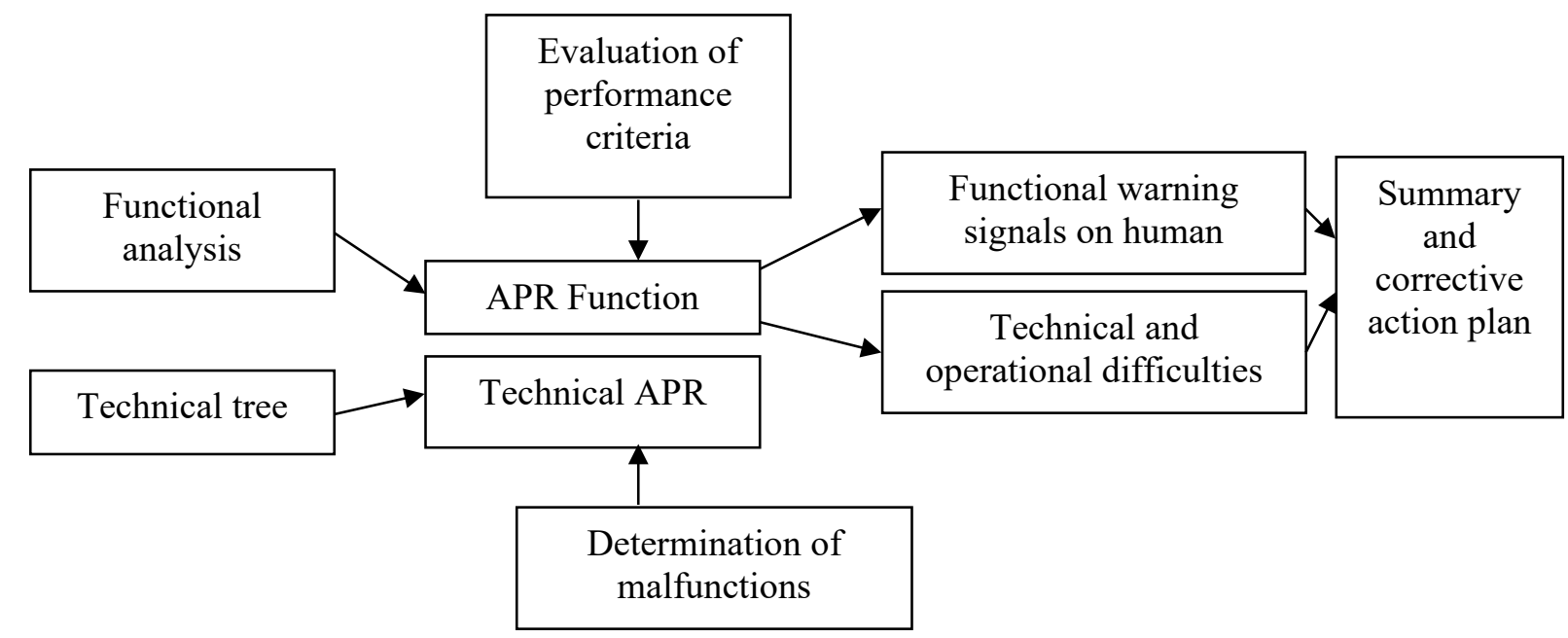

The process then consists in identifying the anxiety-inducing factors and observing all those that would be likely to develop potential risks. We therefore have the following process:

FIGURE 3

ANXIETY RISK IDENTIFICATION PROCESS

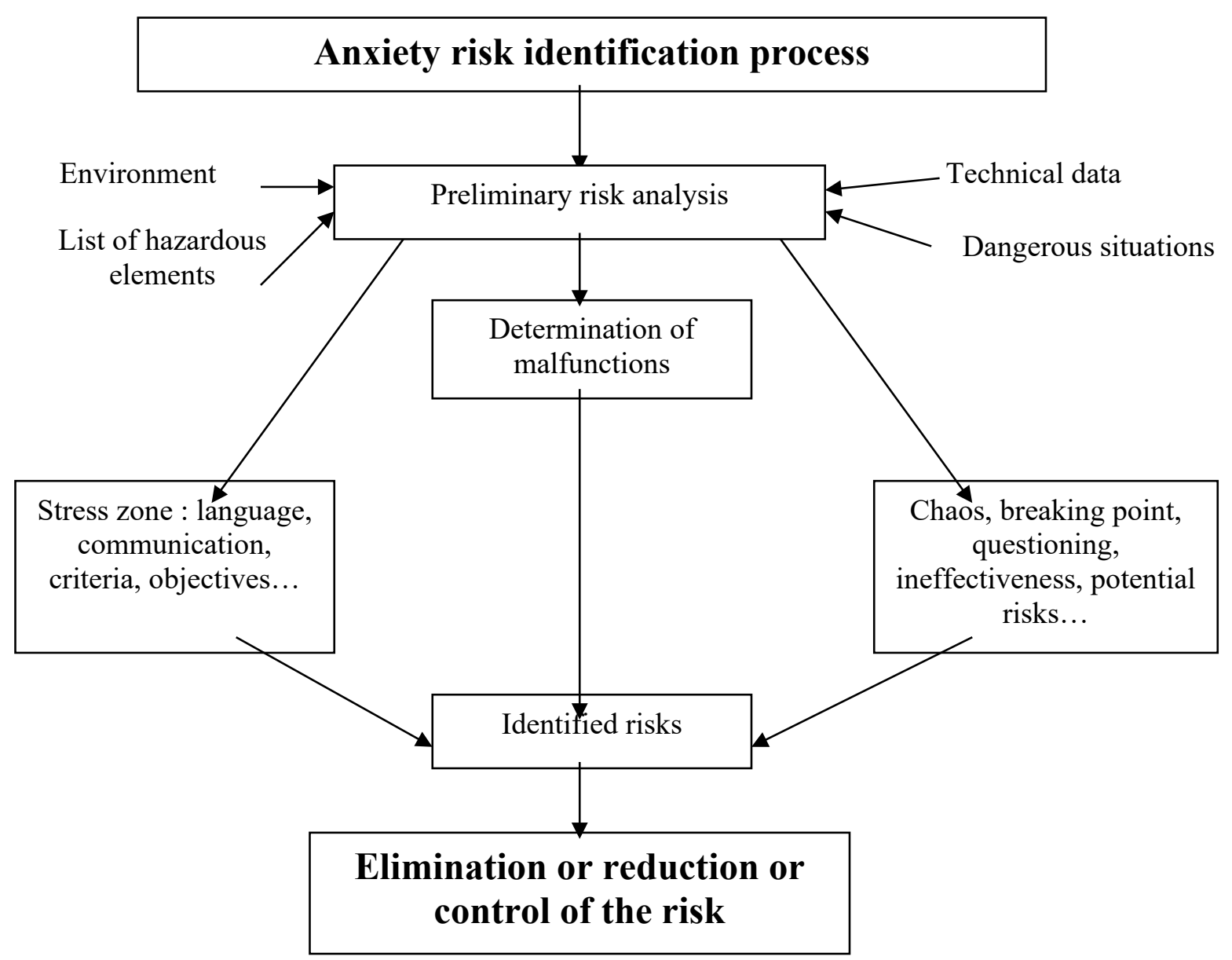


This graphic representation in the form of a tree represents the process by which we propose to identify all the elements likely to induce anxiety-provoking risks due to overly heavy performance management. This pattern develops in a positive way as it allows a way out as soon as the potential risk is identified: it is likely to be mastered, even eliminated, or at least reduced.

The second approach would be to map anxiety-inducing risks using the "fault tree" or "fault trees" method. The ingenuity of this method derives from its graphic representation of anxiety-inducing events that could arise during phases of performance management failures. Its originality should allow us to highlight situations that cause harmful and perverse effects, particularly those harmful to humans as well as to the organization itself. The map is supplemented by a mathematical tool that makes it possible to identify the causes of failures and the probabilities that may develop in the event of anxiety-provoking risks. It also allows us to develop a quantitative matrix of "adverse" events of performance management acts ineffective for the organization, the so-called "dreaded events." We can build the matrix in three levels. The first would be the feared events, the second would come from the identification of adverse events, and the third would come from events that are at the origin of the risks, particularly anxiety-inducing risks.

\section{FIGURE 4}

MODEL OF ANXIETY FAILURE (MDA) AND PSYCHO-SOCIAL RISKS (RPS)

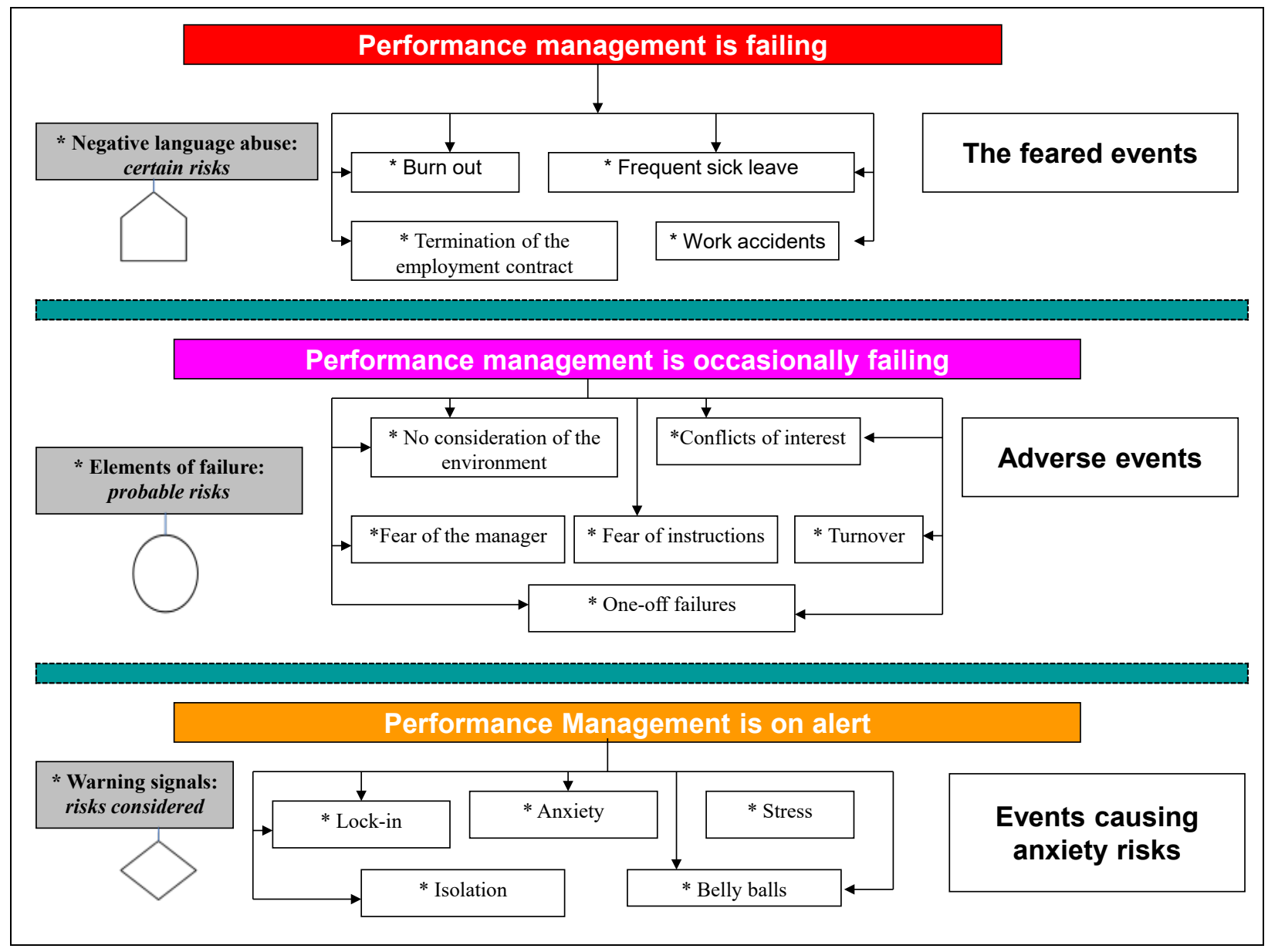

In this diagram, performance management is failing due to a poorly controlled process and nonintegrated warning signals. Three types of symbols are used to identify the different events, which are taken from Bell's model. 


\section{FIGURE 5}

\section{IDENTIFICATION OF EVENTS}

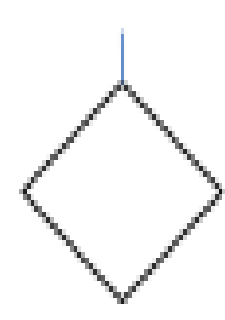

The event occurred but could not develop

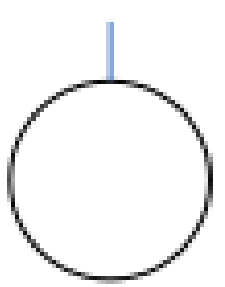

The event has occurred and presents a probable risk of development

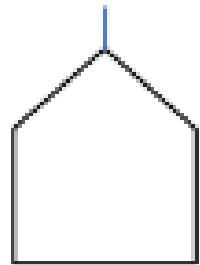

The identified event will occur with certainty

These figures come from the fault tree defined mathematically by Boolean functions, representing indices from the highest to the lowest level of alerts.

At the same time, the positive language elements of performance management can be represented in the following cloud:

\section{FIGURE 6}

\section{LANGUAGE ELEMENTS OF PERFORMANCE MANAGEMENT}

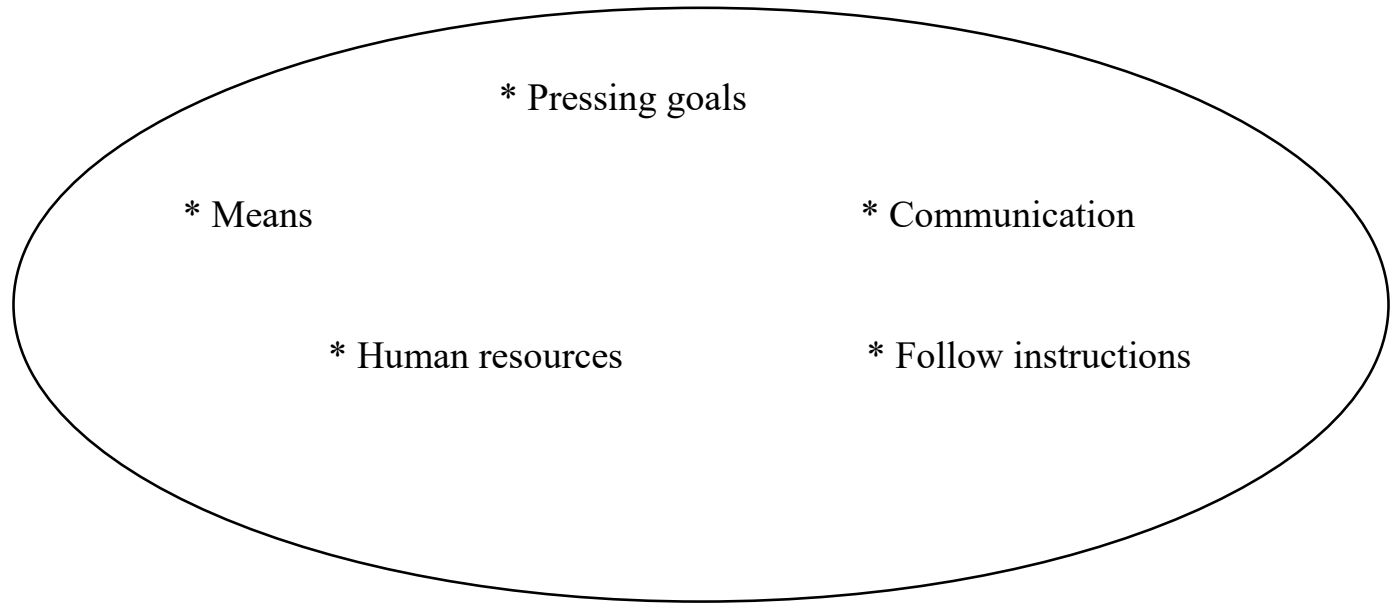

In addition, it can be noted that each individual has a specific reaction to excessive stress and can develop different pathologies.

The same is true of Jensen's model (Principal Agent Theory, known as TPA), for which there are two types of currents: one focused on economic profitability and aimed at performance and the other referring to human psychology and behavioral issues within all organizations. There is a need to integrate a global relationship between the two streams in order to make the organization more efficient. To go further, Jensen describes the four fundamental blocks: the model of human behavior, the costs linked to the transfer of knowledge, the agency costs, and the rules of the organizational game.

At the same time, in order to be effective, performance management must take these four factors into account. Often centered on management and the development of dashboards, this approach presents a 
restrictive vision of the unit's productive capacities. The following tables describe economic realities that are certainly relevant but do not include this dimension of the whole.

\section{FIGURE 7 \\ COMMERCIAL PERFORMANCE MANAGEMENT BOARD}

\begin{tabular}{|l|l|l|l|l|}
\hline Criteria & Objectives & Achievements & \%achievement & $\begin{array}{c}\text { Analysis of } \\
\text { deviation }\end{array}$ \\
\hline Productivity rate & & & & \\
\hline Number of sales & & & & \\
\hline $\begin{array}{l}\text { Number of customers } \\
\text { appointments }\end{array}$ & & & & \\
\hline Number of clients seen & & & & \\
\hline Number of daily sales & & & & \\
\hline Number of monthly sales & & & & \\
\hline Multi-sales Coefficient & & & & \\
\hline
\end{tabular}

We therefore have a numerical and mathematical representation of performance management. The identification of these tables, their appropriation, and acceptance can in some cases be poorly perceived and reflect anxiety-provoking issues that must be identified and taken into account.

This means that the concept of rationality in the very sense of TPA (indicated above) is of a limited type, particularly in humans for reasons and cognitive constraints. It is for this reason that the implementation of rational anticipations to manage limited rationality seems essential to us in order to prevent risks, particularly human risks and those leading, moreover, to the breakdown of an organization.

It follows that a performance management risk assessment method is necessary for the success of any organization regardless of the sector of activity. Performance diagrams and tables are often drawn up on historical indicators that often do not meet future needs. This results in a rupture between the hierarchical modes and the agents concerned, where managers find it difficult to give meaning to the work and to its interest, and to the development of every person. It is appropriate at this stage to consider an alternative model in order to alleviate these risks while integrating them. These are the possible alternative solutions we propose to explore in the next chapter based on a matrix model.

\section{Responses and Alternative Solutions to the Risks Generated}

In our analysis, we highlighted the basics of performance management based on a methodological approach to the culture of results. Nevertheless, it appeared to us that integrating a global performance management approach would take into account all the players who contribute to the result, particularly people and the organization. One cannot be carried out to the detriment of the other, which is what limits performance management and can make it ineffective or even harmful. We have highlighted a number of warning signs that make it possible to anticipate the negative effects of performance management or at least the anxiety-inducing nature that it would be likely to develop in an individual. This is indicated by Goffman's paradigm regarding social structure, organization, and personality. The employee's behavior has a meaning that his manager interprets through the image he wants to give of him. A whole number of gestures, mimicry, and intonation follow that necessarily limit the original information of the personality, especially in a stressful situation. This is what Goffman calls "the grammar of interaction"; in other words, the "work face" or "the work of figuration," which makes it possible to hide in the collaborator his discomfort and allows him to "keep face." This is because the employee will seek to establish a new relationship while seeking to protect themselves.

There is therefore a risk insofar as the employee and his manager will develop a whole system of interactions harmful to the organization and to the desired goals due to the stressful situation felt by one and the incomprehension integrated by the other. 
Under these conditions, it seems necessary to propose an alternative solution to overcome the difficulties encountered by organizations in setting up effective performance management.

The alternative model to remedy the risks must be designed in such a way as to reduce the costs of inefficiency and ineffectiveness of performance management, and thereby create a whole system of balance in order to find the shared interests of each party - shareholders, directors, managers, and employees. The criteria of the model must be based on concrete elements so that they are accessible and understandable to the greatest number.

It is therefore necessary to integrate a transversal modeling, which takes into account the traditionally known criteria on performance but also the part of modeling human behavior without ignoring that this has two aspects: the rational (calculated on the basis of its interests) and the other non-rational (coming from emotions).

We propose a matrix model of type $(m, n)$ with as many lines $m$ from quantifiable data and lines $n$ resulting from human behavior. We can thus develop the performance management matrix as follows.

Either the elements of objectives identified in terms of performance: (A). The A indices are both quantitative and qualitative objective elements.

And (X) the elements of human behavior, which interact on each of the objective points set for the performance of the company. We can write the following system equation:

$$
\begin{gathered}
(\mathrm{K})=(\mathrm{A})(\mathrm{X}) \\
{[(A)][X]=\left|\begin{array}{lll}
a 1 & b 1 & c 1 \\
a & b 2 & c 2 \\
a 3 & b 3 & c 3 \\
a 4 & b 4 & c 4 \\
a 5 & b 5 & c 5
\end{array}\right|\left|\begin{array}{l}
x \\
y \\
z \\
t \\
e
\end{array}\right|=\left|\begin{array}{l}
k 1 \\
k 2 \\
k 3 \\
k 4 \\
k 5
\end{array}\right|=[K]}
\end{gathered}
$$

The optimization of this matrix depends on a globalization of quantitative and qualitative elements as well as human behavior. The interest of such an approach stems from the combination of converging and divergent factors. Following on from this analysis, the work of Baket and Jensen shows great interest in the context of the principal-agent relationship, where they show that everyone has an obligation to stay in their place to advance the organization. The greater the portion assigned to each part, the more efficient the organization becomes.

As an extension of this idea, studies on the modeling of human behavior have shown that it can be broken down "into a decision-action perception loop, reflecting the idea that the chain of command influences human behavior.

Likewise, work on the principles of "capabilities," initiated by Amartya Sen, corrects the idea of "primary social goods" where individuals are not motivated by the acquisition of goods and their social well-being but by the effective possibilities to be able to accomplish their tasks and perform various different acts. In other words, performance management is only effective if it corrects the many inequalities that present obstacles to participation. In order to release individual energy and capacities, it is therefore necessary to allow the release of individual freedoms and energies. Employees are motivated according to four drivers: (1) their well-being in terms of accomplishment; (2) their well-being in terms of freedom; (3) their qualities of accomplishment; and (4) their qualities in terms of freedom. This design therefore shows the need for a transversal approach.

\section{CONCLUSION}

Performance management has established itself over time as an alternative model and as a new paradigm for managing organizations. Although it gives pride of place to the quantitative criteria of activities and results, it does not sufficiently highlight either the conditions by which such results were obtained, or the limited rationality of man. It is in this context that the more management performance is 
driven exclusively by results, the more anxiety it develops in the actor located at the heart of management. These anxiety-provoking factors are likely to destroy an organization.

Our approach consisted in redefining a new reading grid within a global framework for performance management by providing it with more robust measures adapted to the realities of the organizations of the modern century. This approach aims to bring together the approach of rationality and the behaviorist and managerial approach of organizational sciences and cognitive psychology.

Finally, we have proposed a methodological path using clinical studies within organizations that aims to resize the field of management science toward a transversal and multidisciplinary approach. This is what is at stake for the years to come.

\section{ACKNOWLEDGEMENT}

Translated \& edited by American Publishing Services (https://americanpublishingservices.com/).

\section{REFERENCES}

Agbodan, M.M., \& Amoussouga, F.G. (1995). Les facteurs de performance de l'entreprise. John Libbey Eurotext,

Berle \& Means. (1932). The Modern Corporation and Private Property. Library of Congress, Printed in the USA.

Chandler, A.D. (1962). Strategy and Structure: Chapters in the History of Industrial Enterprise.

Charrreaux, G. (2005). « La théorie positive de l'agence: Positionnement et apports ». Revue d'économie industrielle, 4ème trimestre, numéro 112.

Desrocher, A., Baudrin, D., \& Ddadoun, M. (2009). L'Analyse Préliminaire des risques : Principes et pratiques. Ed. Hermès science.

Diehl, B., \& Doublet, G. (2010). Orange: Le déchirement. France Télécom ou la dérive du management, Gallimard.

du Roy, Y. (2009). Orange stressé : Le management par le stress à France Télécom. La Découverte.

Goffman, E. (1991). Les cadres de l'expérience. Paris, Ed. de Minuit, (Coll. « Sens Commun »), pp. 191195.

Hull, J. (2007). Gestion des risques et institutions financières. Pearson.

Laroche, H., \& Nioche, J-P. (2006) « L'approche cognitive de la stratégie d'entreprise ». Revue Française de Gestion, 160.

Lebas, M. (2016). Performance Management and Control. Ed. DUNOD.

Marchesnay, M. (1995). Management Stratégique. Editions de l'ADREG.

Marmuse, C. (1989). Performance. Edition Economica.

Mintzberg, H. (1998). Structure et Dynamique des organisations. Ed. Eyrolles.

Morin, E. (1996). Les indicateurs de performance. Edition GUERIN.

Morin, E., \& Savoie, B.G. (1994). L'efficacité de l'organisation: Théories, représentations et mesures. Edition Gaétan MORIN.

Pesqueux, Y., \& Bonnafous-Boucher, M. (2006). Décider avec les parties prenantes. Edition La Découverte.

Porter, M. (1986). Choix Stratégiques et Concurrence. Economica.

Sen, A. (1987). Ethique et économie. Edition HEC.

Turcotte, P. (2000). Comportement en milieu organisationnel. Edition Sherbrooke. 